\begin{abstract}
HHS Public Access
Author manuscript

J Am Soc Mass Spectrom. Author manuscript; available in PMC 2020 June 01.

Published in final edited form as:

J Am Soc Mass Spectrom. 2019 June ; 30(6): 1126-1132. doi:10.1007/s13361-019-02156-z.

\section{Increasing the Upper Mass/charge Limit of a Quadrupole Ion Trap for Ion/Ion Reaction Product Analysis via Waveform Switching}

\author{
Kenneth W. Lee, Gregory S. Eakins, Mark S. Carlsen, and Scott A. McLuckey \\ Department of Chemistry, Purdue University, West Lafayette, IN 47906-2084
}

Abstract

Quadrupole ion traps (QITs) are versatile platforms for performing experiments with gas-phase ions due to their abilities to store ions of both polarities and to conduct $\mathrm{MS}^{\mathrm{n}}$ experiments. The QIT is particularly useful as a reaction cell for ion/ion reactions. In the case of an ion/ion reaction experiment in a QIT, multiply-charged reactant ions may initially be of relatively low $\mathrm{m} / \mathrm{z}$ (e.g., $\mathrm{m} / z<1000$ ) whereas the product ions can be one or more orders of magnitude higher in $\mathrm{m} / z$ (e.g., $\mathrm{m} / \mathrm{z}>100,000$ ). Several factors can limit the $\mathrm{m} / \mathrm{z}$ range over which an ion/ion reaction experiment can be conducted. These include 1) the efficiency of the detector, 2) the $\mathrm{m} / \mathrm{z}$ range over which oppositely-charged ions can be mutually stored, and 3) the $\mathrm{m} / \mathrm{z}$ range over which ions can be mass-selectively ejected into an external detector. High frequency waveforms provide larger $\mathrm{m} / \mathrm{z}$ trapping ranges for mutual storage of oppositely charged ions whereas low frequency waveforms provide better trapping for very high $\mathrm{m} / \mathrm{z}$ product ions. Presented here is a method that switches from a high frequency sine-wave prior to and during an ion/ion reaction to a low frequency squarewave to eject low $\mathrm{m} / \mathrm{z}$ reagent ions and improve confinement of the product ions before massselective ejection by scanning the frequency of the square-wave. This approach addresses the third issue, which is the primary limiting factor with QITs operated at high RF frequencies (e.g., > 900 $\mathrm{MHz}$.
\end{abstract}

\title{
Graphica Abstract
}

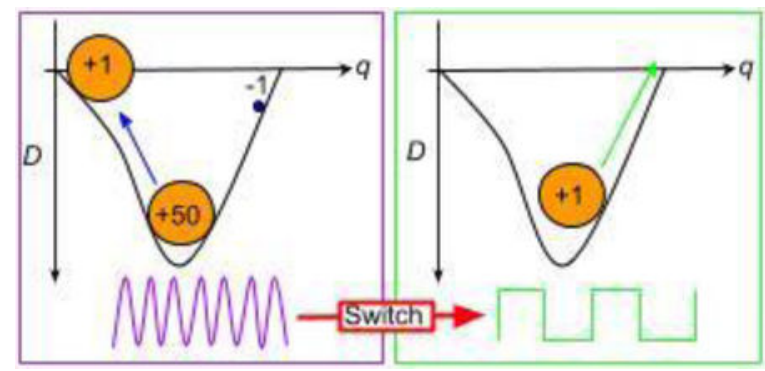

\section{Keywords}

Quadrupole ion trap; ion/ion reactions; digital ion trap; high mass ion

*Address reprint requests to: Dr. Scott A. McLuckey, 560 Oval Drive, Department of Chemistry, Purdue University, West Lafayette, IN 47907-2084, USA, Phone: (765) 494-5270, Fax: (765) 494-0239, mcluckey@ purdue.edu. 


\section{Introduction}

Quadrupole ion traps (QITs), ${ }^{1}$ both 3-D and linear, are widely used in mass spectrometry (MS) in part due to their small size and versatility in executing multi-stage mass spectrometry experiments (i.e., $\mathrm{MS}^{\mathrm{n}}$ ), albeit with moderate-to-low resolution at usual scan rates. ${ }^{2}$ Ion traps are particularly useful as vessels for ionic reactions due to their ability to trap ions of both polarities simultaneously over relatively wide ranges of mass-to-charge $(\mathrm{m} / \mathrm{z})$. This capability has enabled the development of tandem-in-time experiments ${ }^{3}$ involving, for example, collisional activation, ${ }^{4}$ photodissociation, ${ }^{5,6,7}$ and ion/molecule reactions. ${ }^{8}$ The coupling of electrospray ionization (ESI), ${ }^{9,10}$ with its propensity for generating multiply-charged ions from relatively large molecules, with ion traps ${ }^{11}$ has enabled the study of the reactions of oppositely-charged ions. ${ }^{12,13,14}$ Ion/ion reactions, inter alia, have proven to be robust means for charge state manipulation of high mass ions and have been used to facilitate protein mixture analysis, ${ }^{15}$ concentration of multiple chargestates into a single lower charge state, ${ }^{16}$ product ion mass determination following a dissociation reaction, ${ }^{17}$ and inversion of ions from one polarity to another. ${ }^{18}$

Electrospray ionization, due to the multiple-charging effect, tends to generate ions over a relatively narrow $\mathrm{m} / \mathrm{z}$ range. For proteins under denaturing conditions, for example, it is common to observe charge states over a range of $m / z 500-2000 .{ }^{19}$ Under 'native MS' conditions, protein andprotein complex ions can exceed $\mathrm{m} / \mathrm{z} 10,000,{ }^{20}$ although for a given protein or protein complex the charge state distribution tends to be narrow. In any case, ion/ion proton transfer reactions convert lower $\mathrm{m} / \mathrm{z}$ ions to higher $\mathrm{m} / \mathrm{z}$ ions. In the case of $\mathrm{MS}^{\mathrm{n}}$ experiments, it is desirable to generate and transfer ions over a relatively narrow $\mathrm{m} / \mathrm{z}$ range, thereby minimizing mass discrimination effects in the interface, ion transport devices, and the capturing of ions injected into the trap. It is of interest to maximize $\mathrm{MS}^{\mathrm{n}-1}$ performance as well as to optimize the final MS step after ions have been reduced in charge to give high $\mathrm{m} / \mathrm{z}$ ions. Expanding the $\mathrm{m} / \mathrm{z}$ range over which the QIT can be used for mass analysis is desirable for the application of ion/ion reactions to large proteins and protein complexes. The main factors that can limit the upper $\mathrm{m} / \mathrm{z}$ in an ion trap ion/ion reaction experiment using mass-selective instability ${ }^{21}$ for mass analysis are: 1 ) external detector response, 2) the difference in $\mathrm{m} / \mathrm{z}$ ratios of the reagent ions and product ions as well as the range over which both can be stored simultaneously, and 3) the $\mathrm{m} / \mathrm{z}$ range associated with the mass analysis step. In this work, we describe a novel approach to maintaining $\mathrm{MS}^{\mathrm{n}-1}$ performance while improving upon the final MS step by switching from a high frequency sine-wave waveform used for ion accumulation and ion/ion reaction to a low-frequency square-wave for mass analysis in order to address limitations associated with the third potential limitation mentioned above.

\section{Experimental}

\section{Materials.}

Perfluoromethyldecalin (PMD, 512 Da) was purchased from Oakwood Chemicals (Estill, SC). Acetic acid was purchased from Avantor (Radnor, PA). LC/MS grade water was purchased from Fisher Scientific (Hampton, NH). Bovine serum albumin (BSA, 66.4 kDa) 
and Human immunoglobulin $\mathrm{G}$ (IgG, $150 \mathrm{kDa}$ ) were purchased from MilliporeSigma (St. Louis, MO). Solutions ( $1 \mathrm{mg} / \mathrm{mL}$ ) of denatured BSA and IgG were prepared by dissolving them in 99:1 (v/v) water / acetic acid. PMD was placed in a small glass vial, and vapors from the open vial were sampled into the atmospheric sampling glow discharge ionization (ASGDI) source. ${ }^{22}$

\section{Mass Spectrometry.}

This work demonstrates a method to analyze high $\mathrm{m} / z$ ions in a QIT that are initially present at relatively low $\mathrm{m} / \mathrm{z}$ and are transformed to lower z via ion/ion reactions. Nano-electrospray ionization (nESI) was used to introduce highly charged protein cations into the QIT. Subsequent introduction of and mutual storage with oppositely charged reagent ions reduces the charges of the protein ions. Switching the drive RF from a high frequency sine-wave to a low frequency square-wave simultaneously ejects the reagent anions and creates better trapping conditions for the high $\mathrm{m} / \mathrm{z}$ product ions. A frequency scan of the square-wave ejects the product ions according to $\mathrm{m} / \mathrm{z}$ for mass analysis.

To operate the QIT with two different types of waveforms, custom software was developed, and an instrument controller was made. Figure 1 is a schematic of the instrumental setup. All functions were performed by a Hitex Shieldbuddy TC275 (Hitex UK Ltd.) development board. The Shieldbuddy was programmed with the Arduino IDE to understand instructions given to it from a custom Python console program. The instrument controller provided TTL outputs to switch voltages on lenses such that either positive ions from the ESI source or negative ions from the ASGDI source would be transported to the QIT and to trigger detection events. The controller also provided a -10 to $10 \mathrm{~V}$ analog output as a reference value for a custom-built sine-wave generator. A clock input of $1.008 \mathrm{MHz}$ dictated the frequency of the sine-wave. The generated sine-wave was amplified with a tank circuit and connected to the ring electrode of the QIT. Within the controller circuit board, the Shieldbuddy was connected to a direct digital synthesizer (DDS) circuit. The output of the DDS was used as a trigger to a custom-built high voltage pulse generator that was supplied with +200 and $-200 \mathrm{~V}$. The output of the pulse generator was connected to both end cap electrodes of the QIT. Samples of denatured BSA and IgG were introduced to the instrument with nESI using +1000 to $+1500 \mathrm{~V}$ applied to a wire inserted into the back of the emitter capillary. ${ }^{23}$ Perfluoromethyldecalin (PMD) vapor was introduced through tubing into the glow discharge region. Typically -400 to $-500 \mathrm{~V}$ was applied to the front plate to create the discharge.

Figure 2 illustrates a typical scan function. The protein was first introduced to the QIT followed by PMD anions while the sine wave was applied to the ring electrode. After a determined amount of time for the ion/ion reaction (typically hundreds of ms), the resulting post-ion/ion reaction spectrum was obtained either via resonance ejection (sine-wave) or frequency scanning (square-wave). In the case of resonance ejection, a short RF-amplitude ramp from $3,000 \mathrm{~V}$ to $5,050 \mathrm{~V}$ was applied directly after the ion/ion reaction period to eject residual PMD anions. The RF-amplitude was then reduced to as low as $550 \mathrm{~V}$ and scanned up to roughly $5,050 \mathrm{~V}$ while simultaneously applying a resonance ejection signal to the endcap electrodes. In the case of the digital ion trap (DIT) frequency scan, the low frequency 
square wave was applied to the end cap electrodes while the sine wave was still on. After at least $10 \mathrm{~ms}$, the sine wave was turned off. Without this overlap of the two trapping waveforms, significant ion loss was observed. The frequency was scanned down (according to the inverse of the frequency squared) to eject product ions in increasing $\mathrm{m} / \mathrm{z}$ order, linearly. Ions leaving the trap were accelerated to a detector consisting of a conversion dynode and electron multiplier. Because the low frequency waveforms applied to the end caps interfered with the detected signal, the signal was filtered with a low pass RC circuit before being measured. Peaks from collected time spectra were manually fit according to the range of frequencies used and relative peak spacings to determine their $\mathrm{m} / \mathrm{z}$ values, and the time spectra were converted to mass spectra.

Comparison spectra were measured using resonance ejection. Circuitry and scan functions for resonance ejection experiments are not represented. In the case of the resonance ejection scan using low frequencies, the sampling rate of the detection electronics was sufficiently fast to observe individual ion packets that appear as equally spaced peaks with a period corresponding to the ejection frequency.

\section{Results and Discussion}

A traditional sine-wave driven QIT stores ions that simultaneously fall within stability boundaries in the radial and axial dimensions and in regions where the pseudopotential welldepth $^{24}$ is sufficiently deep to avoid ion evaporation from the trap. The dimensionless Mathieu parameters for sine-wave 3-D ion traps are given as: ${ }^{1}$

$$
\begin{aligned}
& a_{z}=\frac{8 e U}{(m / z) \Omega^{2} r_{0}^{2}} \quad a_{r}=\frac{-4 e U}{(m / z) \Omega^{2} r_{0}^{2}} \\
& q_{z}=\frac{-4 e V}{(m / z) \Omega^{2} r_{0}^{2}} \quad q_{r}=\frac{2 e V}{(m / z) \Omega^{2} r_{0}^{2}}
\end{aligned}
$$

where $U$ and $V$ are the DC offset and AC amplitude of the applied waveform, respectively, $\Omega$ is the frequency of the waveform, $r_{O}$ is the radius of the trap, and $\mathrm{m} / \mathrm{z}$ is the mass-to-charge ratio of the ion of interest. Stable solutions are typically represented on a plot of ' $a$ vs. q' This stability diagram predicts if an ion of a particular $\mathrm{m} / \mathrm{z}$ will have stable periodic motion in a trap with a given radius and drive frequency. Most QITs are operated by holding ' $a$ ' equal to zero at all times (i.e., the DC component of the quadrupolar field is $0 \mathrm{~V}$ ). A useful parameter for estimating the effective trapping potential is the so-called potential well depth approximation, $D_{u}$, which, for a sine-wave driven ion trap is given by: ${ }^{25,26}$

$$
D_{u}=0.125 q_{u} V
$$

where $u$ represents $r$ or $z$ and when the condition $q_{u}<0.4$ is satisfied. In the absence of a quadrupolar DC voltage, the upper $\mathrm{m} / \mathrm{z}$ limit for ion storage in a 3-D QIT is determined by $D_{u}$. The upper $\mathrm{m} / \mathrm{z}$ limit for mass analysis, on the other hand, might be further limited by a 
practical constraint, such as the accessible amplitude of the drive RF. For example, a massselective instability scan using boundary ejection from a sine-wave QIT requires sufficient $\mathrm{RF}$ voltage amplitude to bring an ion to $q_{Z}=0.908$. This possible limitation, however, has been circumvented by ejecting ions at much lower $q$-values using resonance ejection. ${ }^{27} \mathrm{~A}$ mass spectrum can be obtained by scanning the RF-amplitude with a fixed supplemental frequency or by scanning the supplemental frequency at a fixed RF-amplitude. ${ }^{2829}$, The former approach leads to ejection at a fixed $q$-value, which facilitates mass calibration and tuning of the resonance ejection voltage, whereas the latter varies the $q$-value ejection point such that the $D_{u}$-values at the ejection point also vary during the scan. An alternative approach is to scan a DC voltage applied to the ring electrode ${ }^{30}$ or to both end-cap electrodes, ${ }^{31}$ referred to as a 'down-scan', leading to a scan of $a$-values that cross the $\beta_{Z}=0$ stability boundary. The down-scan was shown to provide a higher achievable upper $m / z$ limit than a resonance ejection scan on the same platform but with compromised resolution and a non-linear mass scale. ${ }^{28}$

An alternate method of effecting a mass selective instability scan via boundary ejection using a QIT is to ramp the RF frequency at fixed amplitude rather than scanning the amplitude at fixed frequency. ${ }^{32,33,34,35}$ The advantage is that it is possible to generate deeper well-depths for high $\mathrm{m} / \mathrm{z}$ ions under readily accessible voltage conditions using lower drive frequencies. Sine-wave operation for a QIT is usually done at fixed frequency using a tuned circuit to minimize power consumption. Frequency scanning of a QIT, however, is readily accomplished via the switching period between two high voltage sources. Operated in this way, ion traps are often referred to as digital ion traps (DITs) ${ }^{36}$ In the case of a $50 \%$ duty cycle square-wave DIT, the $q_{Z}$-value for boundary ejection is 0.712 and the well-depth at $q_{u}$ $<0.3$ is approximated by: ${ }^{37,38}$

$$
D_{u}=0.206 q_{u} V
$$

For both sine-wave and square-wave operation $D_{Z}=2 D_{r}$ under their respective conditions for which their respective approximations are valid. Thus, $D r$ is the limiting well depth value when operating at low $q$-values.

The objective of this work was to explore the possibility of operating a QIT using a high frequency sine-wave for all stages of a multi-step experiment involving ion/ion reactions up to and including $\mathrm{MS}^{\mathrm{n}-1}$ and then switching to DIT operation for the final mass analysis step. Figure 3(a) shows the post-ion/ion reaction spectrum from the reactions of a distribution of bovine serum albumin (BSA) ions of charge $45^{+}$to $65^{+}$with anions derived from glow discharge ionization of perfluoromethyldecalin (PMD) using a $2.2 \mathrm{kHz}$ resonance ejection frequency $\left(q_{Z}\right.$-value of 0.003$)$ combined with amplitude scanning $(150-300 \mathrm{mV})$ at a fixed sine-wave of $1.008 \mathrm{MHz}$ over an RF amplitude range of $550-5,050 \mathrm{~V}_{0-\mathrm{p}}$. The RF-voltage amplitude during the ion/ion reaction was 3,000 V, which corresponds to a low mass cut-off of $370 \mathrm{Th}$ and $D_{r}=0.9 \mathrm{~V}$ for $\mathrm{BSA}^{+}$. At the end of the ion/ion reaction period, the RF amplitude was ramped to $5,050 \mathrm{~V}$ over a period of $30 \mathrm{~ms}$ to eject residual reagent anions. The insert to Figure 3(a) shows a resonance ejection scan over the RF amplitude range of $2,050-5,050 \mathrm{~V}$ with otherwise identical conditions. Peaks in the measured charge states 
show individual ion packets being ejected at the resonance ejection frequency due to the fast sampling rate of detection electronics. The main spectrum of Figure 3(a) shows signals corresponding to $\mathrm{BSA}^{3+}$ and $\mathrm{BSA}^{2+}$ with no evidence for $\mathrm{BSA}^{+}$. The scanned $m / z$ range corresponded to a nominal $\mathrm{m} / \mathrm{z}$ range of $10,100-92,800$ in $100 \mathrm{~ms}$, yielding an approximate scan rate of $827 \mathrm{kTh} / \mathrm{s}$. However, dropping the RF amplitude to $550 \mathrm{~V}$ to initiate the scan also reduced $D_{r}$ for $\mathrm{BSA}^{+}$to $0.03 \mathrm{~V}$, which could lead to loss of high $\mathrm{m} / \mathrm{z}$ ions. By initiating the scan at $2,050 \mathrm{~V}$, thereby maintaining a minimum $D_{r}$ value of $0.4 \mathrm{~V}$ for $\mathrm{BSA}^{+}$, a weak signal for $\mathrm{BSA}^{+}$could be observed while reducing the scanned $\mathrm{m} / \mathrm{z}$ range to $37,700-$ 92,800 . We found that the $\mathrm{BSA}^{+}$signal disappeared after anions were ejected and RF amplitudes were decreased to less than $2,000 \mathrm{~V}$ prior to scanning, which suggests that $D_{u}$ values of roughly $0.4 \mathrm{~V}$ or greater are needed to store $\mathrm{BSA}^{+}$ions sufficiently well to be observed upon mass analysis. We note that it has been shown that the electric field associated with the presence of a population of low $\mathrm{m} / \mathrm{z}$ ions can assist in the storage of much higher $\mathrm{m} / \mathrm{z}$ ions of opposite polarity, which has been termed 'trapping by proxy'. ${ }^{39}$ This phenomenon may occur during the mutual storage ion/ion reaction period, but does not occur during the mass analysis step as the anions are removed prior to scanning. We anticipate that there is a range of $D_{u}$ values over which ion storage and ejection efficiencies increases from zero to a maximum value.

Figure 3(b) shows the ion/ion product ion spectrum using the same mutual ion storage conditions for the ion/ion reaction as those for Figure 3(a) using a DIT boundary ejection frequency scan of $100-19 \mathrm{kHz}$ at an amplitude of $\pm 200 \mathrm{~V}$. Because the switch to the low frequency square-wave created a high LMCO, no extra step was needed to eject residual reagent anions prior to mass analysis. The scan covered a nominal $\mathrm{m} / \mathrm{z}$ range of $3,200-$ 88,600 . This spectrum shows strong signals for both $\mathrm{BSA}^{2+}$ and $\mathrm{BSA}^{+}$, which indicates that the mutual storage conditions were able to trap $\mathrm{BSA}^{+}$ions with good efficiency. The low $\mathrm{BSA}^{+}$signal associated with the insert of Figure 3(a) is therefore interpreted as arising from poor resonance ejection efficiency. The size of the trapped ion cloud is inversely related to well-depth. We expect radial confinement of the ion cloud to be more important than axial confinement in determining ejection efficiency, therefore the ion cloud may be radially too large to be ejected efficiently through the exit aperture of the end-cap electrode with a $D_{r}$ value of $1.4 \mathrm{~V}$. In the case of the frequency scan, the $D_{r}$ value for BSA ${ }^{+}$was $0.7 \mathrm{~V}$ at 100 $\mathrm{kHz}$ and increased to roughly $15 \mathrm{~V}$ at its ejection frequency of $22.06 \mathrm{kHz}$. The factor of ten increase in $D_{r}$ may account for the increase in observed signal. The increased confinement prior to ejection might also account for the noticeably narrower charge states measured by the frequency scan. Therefore, the limitation associated with the BSA experiment using resonance ejection at a low $q_{Z}$-value is overcome by using a DIT RF frequency scan with boundary ejection at $q_{Z}=0.712$.

Using DIT operation for mass analysis provided ample well depths for high $\mathrm{m} / \mathrm{z}$ ions that were missing in resonance ejection scans at low $q_{Z}$-values, which allowed us to identify the next limiting factor for high $\mathrm{m} / \mathrm{z}$ performance of an ion/ion reaction in the current QIT. Figure 4(a) shows the postion/ion reaction frequency scan for human IgG following a 300 $\mathrm{ms}$ ion/ion reaction period. Note that the $\mathrm{IgG}^{3+}, \mathrm{IgG}^{2+}$, and $\mathrm{IgG}^{+}$charge states are observed. When the reaction period was extended to $500 \mathrm{~ms}$, the spectrum of Figure 4(b) was obtained. Note that while the $\mathrm{IgG}^{3+}$ signal was totally depleted and the $\mathrm{IgG}^{2+}$ ion was also 
largely depleted, the $\operatorname{IgG}^{+}$absolute signal was little changed from the data obtained in Figure 4(a). This suggests that the mutual storage conditions are marginally effective for storing both the PMD anions and singly charged $\mathrm{IgG}^{+}$ions. The $D_{r}$ value for the $\mathrm{IgG}^{+}$ion under the mutual storage conditions was $0.4 \mathrm{~V}$, which is the minimum well depth needed to store ions based on our studies with BSA.

\section{Conclusions}

Gas-phase ion/ion reactions can present particularly challenging demands on the $m / z$ range of a QIT due to the wide range of ion $\mathrm{m} / \mathrm{z}$ ratios that can be relevant to a particular combination of reactants and products. The charge reduction of initially highly charged bioions and bio-ion complexes to ions of relatively low charge states presents such a challenge, especially when the reagent ions used for charge transfer are of low $\mathrm{m} / \mathrm{z}$ ratio. The $\mathrm{m} / \mathrm{z}$ range of a QIT is limited at the low end by the so-called low-mass cut-off, which, in the absence of a DC field, is determined by the $z$-dimension exclusion limit. This is the point at which ions reach $q_{Z}=0.908$ in a sine-wave driven QIT and $q_{Z}=0.712$ for a square-wave driven QIT. The performance of a QIT used as a reaction vessel and analyzer for an ion/ion reaction at high $\mathrm{m} / \mathrm{z}$ values using mass selective instability can be limited by the performance of the detector, the ability to store both reactants and products simultaneously, and the approach used to scan the ions from the ion trap. Resonance ejection at low $q_{Z}$-values can minimize the RF voltage amplitude needed for ion ejection but leads to shallow well-depths that can result in ion evaporation or an ion cloud size that exceeds the dimensions of the exit aperture of the ion trap. Product ions can be ejected at lower voltages and from deeper well-depths if the RF frequency is reduced. We show here an extension by a factor of 2-3 in upper $\mathrm{m} / \mathrm{z}$ limit via mass selective instability by switching from high frequency sine-wave QIT operation to square-wave digital ion trap operation with frequency scanning for mass analysis after an ion/ion reaction period. In the present system using DIT operation for mass analysis, the mutual storage conditions during the ion/ion reaction period becomes the limiting factor in upper $\mathrm{m} / \mathrm{z}$ performance.

\section{Acknowledgements}

This work was supported by the National Institutes of Health (NIH) under Grant GM R37-45372. Dr. Jeixun Bu and Dr. Eric Dziekonski are acknowledged for initiating our efforts with DIT technology as is the Purdue Chemistry Department's Jonathan Amy Facility for Chemical Instrumentation for its role in developing and building the custom electronics used in this research.

\section{References}

1. Quadrupole Ion Trap Mass Spectrometry, 2nd Edition, March RE and Todd JFJ, Wiley Interscience, Hoboken, NJ, 2005

2. Louris JN, Brodbelt-Lustig JS, Cooks RG, Glish GL, Van Berkel GJ, McLuckey SA, Sequential Stages of Mass Spectrometry in a Quadrupole Ion Trap Mass Spectrometer. Int. J. Mass Spectrom. Ion Proc, 96, 117-137 (1990)

3. Johnson JV, Yost RA, Kelley PE, Bradford DC, Tandem-in-space and tandem-in-time mass spectrometry: triple quadrupoles and quadrupole ion traps. Anal. Chem 62, 2162-2172 (1990)

4. Louris JN, Cooks RG, Syka JEP, Kelley PE, Stafford GC, Todd JFJ, Instrumentation, applications, and energy deposition in quadrupole ion-trap tandem mass spectrometry. Anal. Chem 59, 16771685 (1987) 
5. Brodbelt JS, Wilson JJ, Infrared multiphoton dissociation in quadrupole ion traps. Mass Spectrom. Rev 28, 390-424 (2009) [PubMed: 19294735]

6. Louris JN, Brodbelt JS, Cooks RG, Photodissociation in a quadrupole ion trap mass spectrometer using a fiber optic interface. Int. J. Mass Spectrom. Ion Processes 75, 345-352 (1987)

7. Brodbelt JS, Photodissociation mass spectrometry: New tools for characterization of biological molecules. Chem. Soc. Rev 43, 2757-2783 (2014) [PubMed: 24481009]

8. Vedel F, Vedel M, Brodbelt JS Ion/Molecule Reactions, Practical Aspects of Ion Trap Mass Spectrometry, March RE, Todd JFJ (Eds.), Vol 1, Ch. 8, CRC Press Boca Raton, 1995.

9. Fenn J, Mann M, Meng C, Wong S, Whitehouse C, Electrospray ionization for mass spectrometry of large biomolecules. Science 246, 64-71 (1989) [PubMed: 2675315]

10. Smith RD, Loo JA, Edmonds CG, Barinaga CJ, Udseth HR, New developments in biochemical mass spectrometry: electrospray ionization. Anal. Chem 62, 882-899 (1990) [PubMed: 2194402]

11. Van Berkel GJ, Glish GL, McLuckey SA, Electrospray Ionization Combined with Ion Trap Mass Spectrometry Anal. Chem, 62, 1284-1295 (1990)

12. McLuckey SA; Stephenson JL Jr., Ion/Ion Chemistry of High-Mass Multiply Charged Ions. Mass Spectrom. Rev 17, 369-407 (1998) [PubMed: 10360331]

13. Pitteri SJ, McLuckey SA, Recent Developments in the Ion/Ion Chemistry of High-Mass Multiply Charged Ions. Mass Spectrom. Rev 24, 931-958 (2005) [PubMed: 15706594]

14. Prentice BM, McLuckey SA, Gas-Phase Ion/Ion Reactions of Peptides and Proteins: Acid/Base, Redox, and Covalent Chemistries. Chem. Commun 49, 947-965 (2013)

15. Stephenson JL Jr., McLuckey SA, Ion/ion Reactions for Oligopeptide Mixture Analysis: Application to Mixtures Comprised of 0.5-100 kDa Components. J. Am. Soc. Mass Spectrom 9, 585-596 (1998) [PubMed: 9879372]

16. McLuckey SA, Reid GE, Wells JM, Ion Parking During Ion/ion Reactions in Electrodynamic Ion Traps. Anal. Chem 74, 336-346 (2002) [PubMed: 11811406]

17. Stephenson JL Jr., McLuckey SA, Simplification of Product Ion Spectra Derived from MultiplyCharged Parent Ions via Ion/Ion Chemistry. Anal. Chem 70, 3533-3544 (1998) [PubMed: 9737205]

18. He M, Emory JF, McLuckey SA, Reagent Anions for Charge Inversion of Polypeptide/Protein Cations in the Gas Phase. Anal. Chem 77, 3173-3182 (2005) [PubMed: 15889906]

19. Konermann L, Ahadi E, Rodriguez AD, Vahidi S, Unraveling the Mechanism of Electrospray Ionization. Anal. Chem 85, 2-9 (2013) [PubMed: 23134552]

20. Leney AC, Heck AJR, Native Mass Spectrometry: What is in the Name? J. Am. Soc. Mass Spectrom 28, 5-13 (2017) [PubMed: 27909974]

21. Stafford GC Jr., Kelley PE, Syka JEP, Reynolds WE, Todd JFJ, Recent Improvements in and Analytical Applications of Advanced Ion Trap Mass Spectrometry. Int. J. Mass Spectrom. Ion Processes 60, 85-98 (1984)

22. McLuckey SA, Glish GL, Asano KG, Grant BC, Atmospheric Sampling Glow Discharge Ionization Source for the Analysis of Trace Organics in Ambient Air. Anal. Chem, 60 2220-2228 (1988)

23. Van Berkel GJ, Asano KG, Schnier PD, Electrochemical processes in a wire-in-a-capillary bulkloaded, nano-electrospray emitter. J. Am. Soc. Mass Spectrom 12, 853-862 (2001) [PubMed: 11444609]

24. Douglas DJ, Berdnikov AS, Konenkov NV, The effective potential for ion motion in a radio frequency quadrupole field revisited. Int. J. Mass Spectrom 377, 345-354 (2015)

25. Wuerker RF, Shelton H, Langmuir RV Electrodynamic containment of charged particles. J. Appl. Phys 30, 342-349 (1959)

26. Dehmelt HG Radiofrequency spectroscopy of stored ions I: Storage In Bates DR (Ed.), Advances in Atomic and Molecular Physics, Vol. 3, Academic New York, 1967, 53-72.

27. Kaiser RE Jr., Cooks RG, Stafford GC Jr., Syka JEP, Hemberger PH, Operation of a Quadrupole Ion Trap Mass Spectrometer to Achieve High Mass/Charge Ratios. Int. J. Mass Spectrom. Ion Processes 106, 79-115 (1991) 
28. Nie Z, Cui F, Chu M, Chen C-H, Chang H-C, Cai Y, Calibration of a frequency-scan quadrupole ion trap mass spectrometer for microparticle mass analysis. Int. J. Mass Spectrom 270, 8-15 (2008)

29. Snyder DT, Pulliam CJ, Wiley JS, Duncan J, Cooks RG, Experimental Characterization of Secular Frequency Scanning in Ion Trap Mass Spectrometers. J. Am. Soc. Mass Spectrom 27, 1243-1255 (2016) [PubMed: 27032650]

30. Todd JFJ; Penman AD; Smith RD, Some alternative scanning methods for the ion trap mass spectrometer. Int. J. Mass Spectrom. Ion Processes 106, 117-135 (1991)

31. Prentice BM, McLuckey SA, Analysis of High $\mathrm{m} / \mathrm{z}$ Ions in a Quadrupole Ion Trap Mass Spectrometer via an End-cap Quadrupolar DC Downscan. Anal. Chem, 84, 7562-7569 (2012) [PubMed: 22881346]

32. Schlunegger UP, Stoeckli M, Caprioli RM, Frequency scan for the analysis of high mass ions generated by matrix-assisted laser desorption/ionization in a Paul trap. Rapid Commun. Mass Spectrom 13, 1792-1796 (1999) [PubMed: 10482890]

33. Landais B, Beaugrand C, Capron-Dukan L, Sablier M, Simonneau G, Rolando C, Varying the radio frequency: a new scanning mode for quadrupole analyzers. Rapid Commun. Mass Spectrom 12, 302-306 (1998)

34. Ding L, Sudakov M, Kumashiro S, A simulation study of the digital ion trap mass spectrometer. Int. J. Mass Spectrom 221, 117-138 (2002)

35. Ding L, Sudakov M, Brancia FL, Giles R, Kumashiro S, A digital ion trap mass spectrometer coupled with atmospheric pressure ion sources. J. Mass Spectrom 39, 471-484 (2004) [PubMed: 15170743]

36. Hoffman NM, Gotlib ZP, Opacic B, Huntley SP, Moon AM Donahoe KEG, Brabeck GF, Reilly PTA, Digitial Waveform Technology and the Next Generation of Mass Spectrometers. J. Am. Soc. Mass Spectrom 29, 331-341 (2018) [PubMed: 28971335]

37. Brancia FL, Ding L, Rectangular Waveform Driven Digitial Ion Trap (DIT) Mass Spectrometer: Theory and Applications Practical Aspects of Ion Trap Mass Spectrometry, March RE, Todd JFJ. (Eds.), Vol IV, Ch. 4, CRC Press, Boca Raton, 2010.

38. Reilly PTA, Brabeck GF, Mapping the pseudopotential well for all values of the Mathieu parameter $\mathrm{q}$ in digital and sinusoidal ion traps. Int. J. Mass Spectrom 392, 86-90 (2015).

39. McLuckey SA, Wu J, Bundy JL, Stephenson JL, Hurst GB, Oligonucleotide Mixture Analysis via Electrospray and Ion/Ion Reactions in a Quadrupole Ion Trap. Anal. Chem 74, 976-984 (2002) [PubMed: 11925000] 


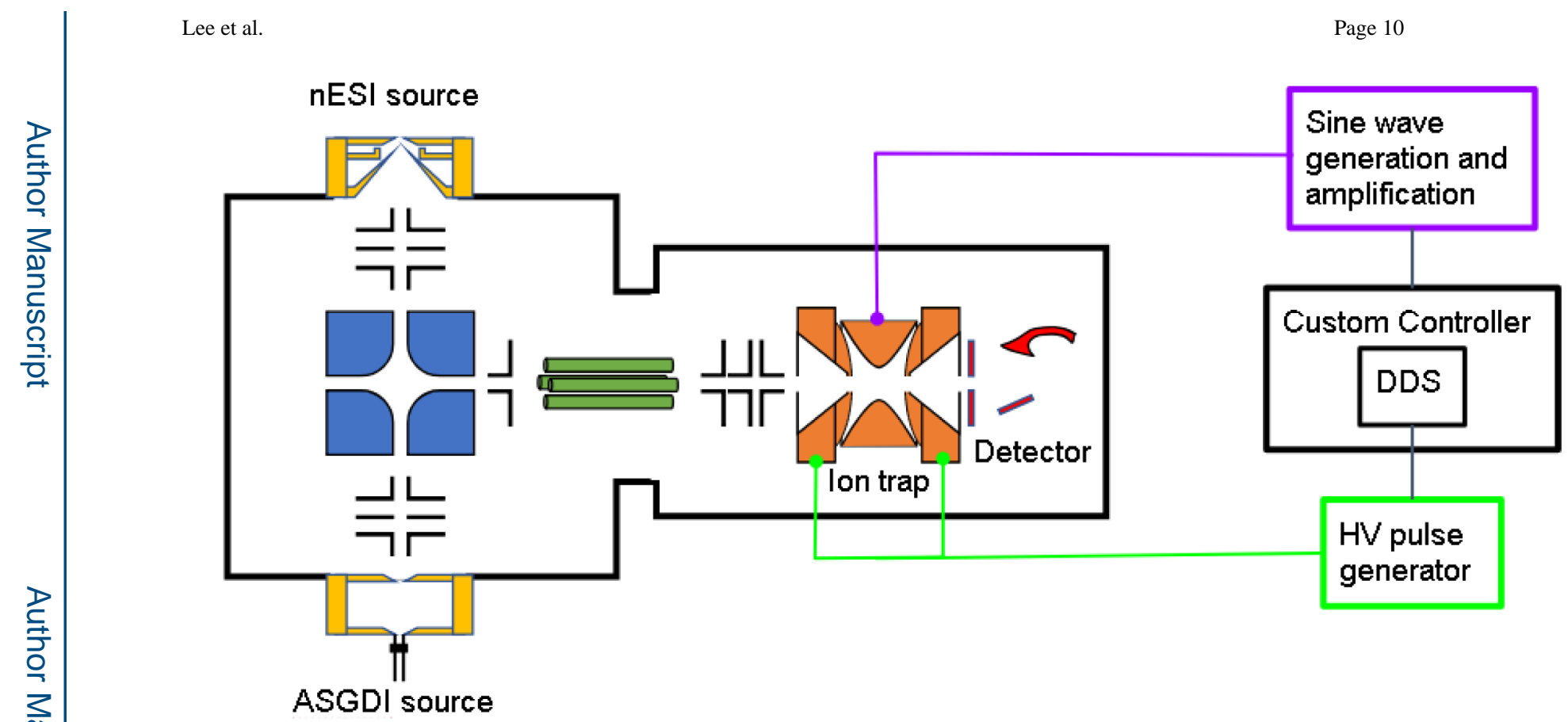

Figure 1.

Schematic of instrumental setup for waveform switching experiments. A high frequency sine wave is applied to the ring electrode during ion injection and mutual storage to provide adequate trapping of low $\mathrm{m} / \mathrm{z}$ reagent and analyte ions and high $\mathrm{m} / \mathrm{z}$ product ions. A low frequency square wave is applied to the end cap electrodes during mass analysis to provide better confinement of very high $\mathrm{m} / \mathrm{z}$ product ions prior to mass selective ejection. 


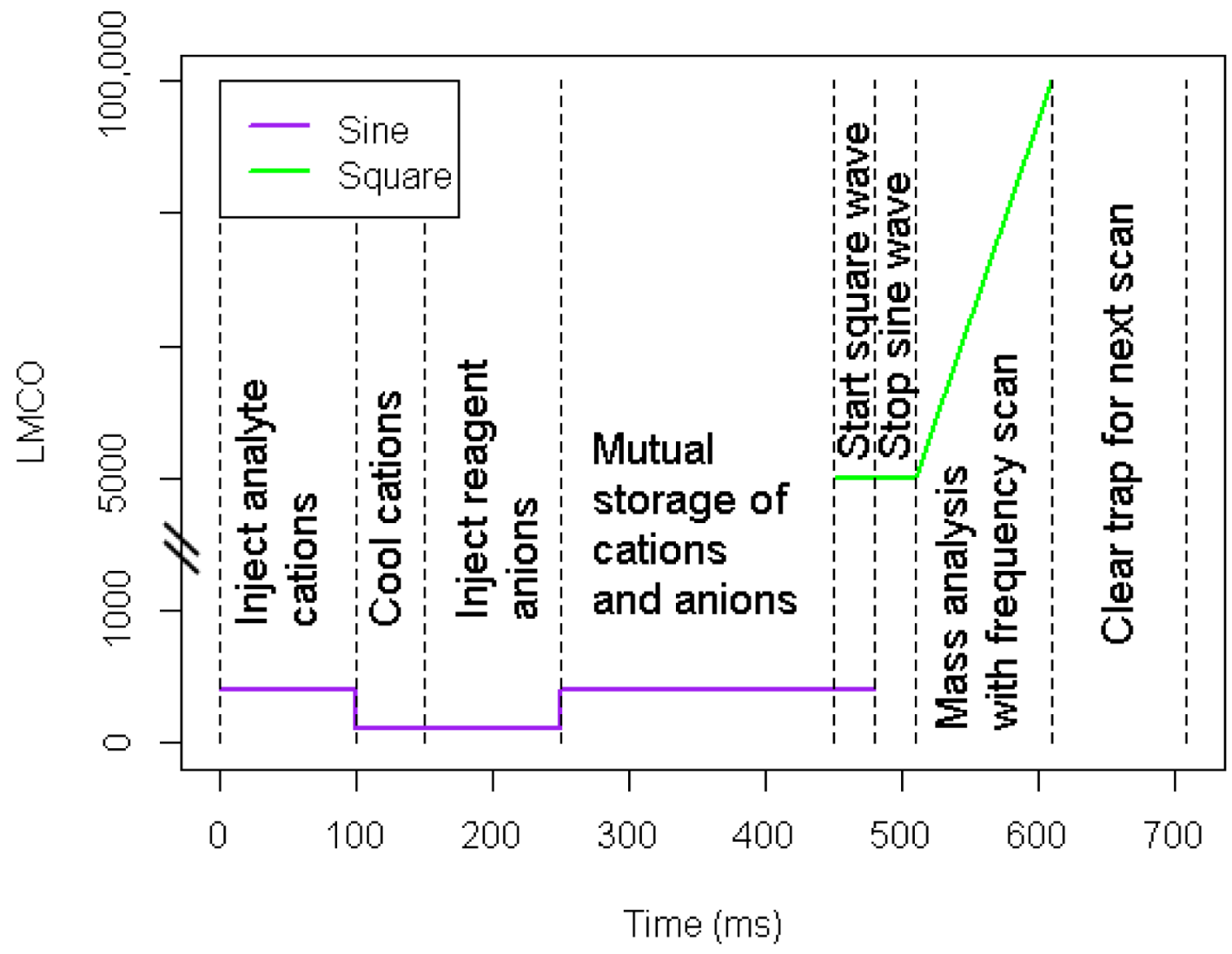

Figure 2.

Typical scan function for waveform switching experiment. A high frequency sine wave traps analyte and reagent ions during injection and mutual storage. At the end of the mutual storage step, a low frequency square wave is applied to provide better trapping of high $\mathrm{m} / \mathrm{Z}$ product ions. The sine wave is then turned off, and mass analysis is accomplished with a frequency scan of the square wave. 


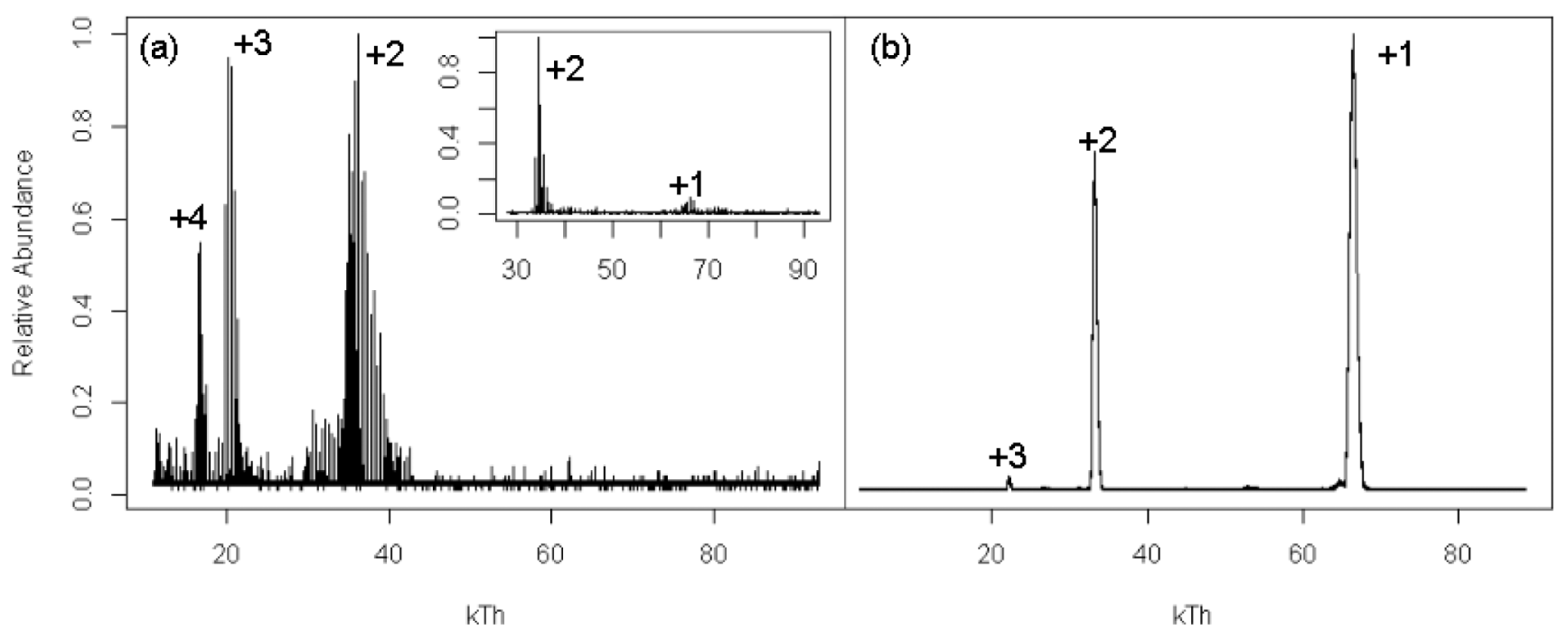

Figure 3.

Product ions of the BSA and PMD ion/ion reaction measured with (a) resonance ejection and (b) waveform switching. Resonance ejection was performed using a RF ramp of 550 to $5,050 \mathrm{~V}$ at $1.008 \mathrm{MHz}$ and a dipolar waveform at $2.2 \mathrm{kHz}$ with a scan length of $100 \mathrm{~ms}$. The spectrum in the insert was measured starting the RF ramp at $2 \mathrm{kV}$ and a scan length of 50 $\mathrm{ms}$. The DIT frequency scan was performed using a $\pm 200 \mathrm{~V}$ square wave scanned linearly in $\mathrm{m} / \mathrm{z}$ (nonlinearly in frequency) from 100 to $19 \mathrm{kHz}$ over $50 \mathrm{~ms}$. 

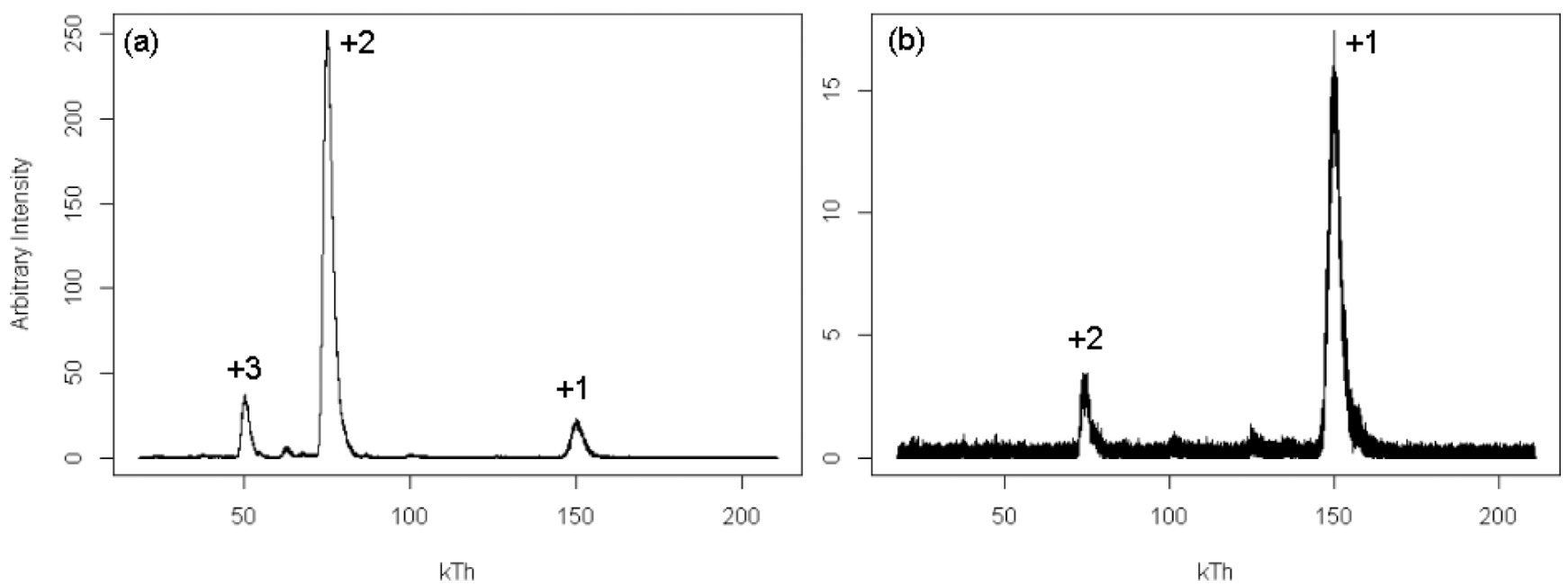

Figure 4.

Post-ion/ion reaction mass spectrum between PMD anions and human IgG using DIT frequency scanning after (a) $300 \mathrm{~ms}$ mutual storage time at an RF voltage of 3,200 V during the reaction period and (b) $500 \mathrm{~ms}$ mutual storage time at the same RF voltage. Both spectra were measured using a $\pm 200 \mathrm{~V}$ square wave scanned linearly in $\mathrm{m} / \mathrm{z}$ (nonlinearly in frequency) from 40 to $12 \mathrm{kHz}$. 